\title{
Becoming a Movement Society? Patterns in the Public Acceptance of Protest, 1985 - 2006
}

Soon Seok Park and Rachel L. Einwohner

Sociological Focus 52(3): XX-XX.

(DOI: 10.1080/00380237.2019.1624233)

ABSTRACT A social movement society refers to a society in which protest is a standard, institutionalized feature of the political landscape. Is the U.S. steadily becoming such a society? Whereas other empirical tests of the movement society thesis have focused on political tactics and individual participation in protest, we point to the public's attitudes as another indicator of the movement society. Using General Social Survey data, we find that the public has grown more accepting of protest with time. In addition, using indicators of social location, social engagement, and political engagement as predictors, we find that while these factors help explain support for protest, their effects vary depending on the type of protest in question. Age, education, gender, income, employment status, and political interest all affect the acceptance of public meetings and demonstrations; however, the effect of income is reversed when it comes to the acceptance of a nationwide strike. Lastly, an age-period-cohort analysis finds evidence that a period effect is greater than a cohort effect in changing attitudes over time. Taken together, these findings support the claim that broad, societal-level influences have contributed to the public acceptance of protest, which is suggestive of a social movement society. Yet while the U.S. may constitute a social movement society, it is one with clear boundaries: individuals do support protest, but only to the extent that it does not disrupt the material advantages associated with their social location.

Keywords: protest, social movement society, public opinion, age-period-cohort analysis

Soon Seok Park is a PhD Candidate in the Department of Sociology at Purdue University. His research interests lie in the areas of social movements, political sociology, and international political economy. His work has appeared in Social Movement Studies and Sociological Perspectives. He is currently completing his dissertation, an examination of the Korean Democracy Movement between 1980 and 1987.

Rachel L. Einwohner is Professor of Sociology and (by courtesy) Political Science at Purdue University. Her research focuses on the dynamics of protest and resistance, both in the contemporary U.S. and other national and historical settings. She is co-editor (with Holly J. McCammon, Verta Taylor, and Jo Reger) of The Oxford Handbook of U.S. Women's Social Movement Activism (Oxford University Press, 2017).

Contact: Soon Seok Park*, Department of Sociology, Purdue University, 700 W. State Street, West Lafayette, IN 47907; park460@purdue.edu

Acknowledgements: An earlier version of this article was presented at the 2015 American Sociological Association annual meeting in Chicago, IL. We thank the audience members at that session for their comments. We also thank James G. Anderson, Shawn Bauldry, Kenneth Ferraro, Jong Hyun Jung, Miao Li and the editor and anonymous reviewers for their helpful comments and advice. 


\section{Becoming a Movement Society? Patterns in the Public Acceptance of Protest, 1985 - 2006}

The widespread protest that has occurred since Donald Trump's 2017 inauguration provides a powerful illustration of the myriad ways in which protesters come together to air grievances and press for social change. Protesters have participated in public meetings in their towns, in marches and demonstrations in many cities and states, and have organized various nationwide strikes such as the "Day Without Immigrants" and the March 8, 2017 Women's Strike. Though they may vary widely, all acts of protest share the goal of communicating an oppositional message to some external audience (Jasper 1997), such as targets or authorities. In this article we examine protest from the perspective of one of those audiences: the general public. Specifically, we use data from the General Social Survey (GSS) to analyze the public acceptance of protest. We ask: does the public accept protest? Has the acceptance of protest changed over time? If the acceptance of protest has changed over time, what is driving that change? And what predicts whether or not members of the public find protest acceptable?

These questions allow us to engage in a critical examination of a theoretical concept from the field of social movements: the notion of a "social movement society," or a society in which protest has become a routine, institutionalized feature of the political landscape (Meyer and Tarrow 1998; Soule and Earl 2005; Tarrow 1994). While scholars studying movement societies have examined various aspects of politics and political behavior, including political organizations, protest tactics, and individual participation in protest, relatively few scholars working with this concept have explored the extent to which protest is acceptable in the eyes of the general public (for an exception see Crozat 1998). Our inquiry therefore serves as a further test of the "movement society" hypothesis.

Beyond its relevance to discussions about movement societies, we argue that our inquiry is useful for several reasons. Most generally, by focusing on external movement audiences, this examination helps address the criticism that social movement research is too "movementcentric" (McAdam and Boudet 2012). Relatedly, a study of the public acceptance of protest activity helps further our understanding of the environment in which movements operate. Social movement scholars have long recognized the importance of the political environment for the success of social movements (e.g., McAdam 1982; McAdam, McCarthy, and Zald 1996). Because public opinion is a feature of the political environment, it may therefore be relevant to a movement's abilities to succeed (Burstein and Linton 2002; Thomas and Louis 2014). Further, the acceptance of protest may itself be an outcome of social movements as a whole. Of course, social movement groups strive to achieve their substantive goals. Yet public acceptance of the movement's method of political expression, above and beyond the movement's particular stated goals, may be understood as an implicit, collective goal shared by all movements.

As we note in more detail below, our study examines the public's acceptance of three different types of protest activity, which may be characterized as having increasing amounts of potential for societal disruption: public meetings, marches and demonstrations, and general strikes. We do so in recognition of the premise that as acts of protest vary widely, so too can their 
level of acceptability. Previous research conceptualized such variations in terms of risk or cost, especially in reference to the experiences of movement participants (McAdam 1988; Nepstad and Smith 1999). In contrast, what may be relevant or salient for the public is the level of social disruption associated with various acts of protest. That is, the public may view more contentious forms of protest differently than those that cause less disruption. As Crozat (1998: 60) notes, "If protest draws its strength from its contentious nature, then the degree of contentiousness matters."

We begin by reviewing the extant work on the concept of the "movement society" and argue that this research may be extended with an examination of public opinion about protest. We then present our data, which come from four different years of data collected from the GSS, and our analyses. We end with a discussion of the implications of our findings for future research.

\section{The Social Movement Society, Protest, and the Public}

Meyer and Tarrow (1998:6) note that an overall decline in violence in collective action in Western Europe and North America, coupled with an increase in the abilities of "ordinary people" to stage collective action, suggests that protest may enjoy "acceptability and even legitimation by elites and authorities." This insight is reflected in their concept of a "social movement society," one in which protest is routinized and accepted (Meyer and Tarrow 1998; Meyer and Pullum 2015; Taylor 2000). The introduction of this concept has inspired scholars to examine the institutionalization of protest, including the ways in which protesters who "follow the rules" enjoy access to political decision-making (Meyer 1993), the extent to which protesters use "insider" or "outsider" tactics (Soule and Earl 2005), and the ways in which activism has become part of the corporate world, such as through cause lawyering (Boutcher 2013). An additional line of work on movement societies explores participation in protest as an indicator of the movement society, inquiring both about individuals' potential for participation in protest (Jenkins, Wallace, and Fullerton 2008) and whether actual participation has increased over time (Caren, Ghoshal, and Ribas 2011).

We argue for the study of public opinion as another lens with which to view movement societies. Public opinion has received a fair amount of attention among social movement researchers. To a certain extent, public opinion can serve as an indicator of a social movement. For instance, McCright and Dunlap (2008) use public opinion data to find evidence of progressive social movement ideology. Scholars primarily interested in social movement outcomes have also incorporated public opinion centrally in their work, examining it either as a direct consequence of movement activity (Berkowitz 1973) or as a factor that combines with movement activity to produce other changes of interest, such as policy change (Agnone 2007; Burstein 1979; Burstein and Freudenburg 1978; Jacobs and Kent 2007; McAdam and Su 2002; Weaver 2008). More to the point of our inquiry, some studies have focused on public attitudes about protest itself (as distinct from attitudes about political causes associated with particular movements). Written during the height of turbulent 1960s, a number of earlier studies concerned 
themselves with public reactions to protest activity, including examinations of whether the public saw the collective action of the time as "protest" or "riots" (see Turner 1969). Such work either explicitly or implicitly focused on the legitimacy of collective action: defining action as "protest" carried a positive connotation, interpreting it as a legitimate expression of valid grievances, whereas the label "riot" implied criminality or other deviance.

The concept of a movement society rests on the notion that protest is a standard, accepted feature of the political landscape. If a movement society exists, then, it should be reflected in public attitudes about protest. Those who find protest acceptable may be exhibiting a form of "weak support" for movements (Ennis and Schreur 1987). Even the attitudes of members of the public who neither support nor oppose social movements are relevant to a social movement society. Such attitudes held by the "bystander public," or the segment of the public that does not necessarily act for or against social movements, are taken into account when movements plan strategy (Turner 1970). By "witnessing” movement activity (McCarthy and Zald 1977: 1221), and having opinions about the legitimacy (or illegitimacy) of protest, such publics can therefore provide further evidence of a movement society.

In what follows, we use public opinion data from national polls to inquire about the presence and character of a social movement society. We acknowledge that "public opinion" is a complex concept that is often inadequately measured by polls (Manza and Brooks 2012; Perrin and McFarland 2011). Our modest goals are to inquire about changing attitudes about protest, as captured by national polls (in our case, the General Social Survey). Thus, we do not claim that these data fully express the public's opinions about protest behavior. However, we find utility in examining changes in these survey results over time, as we believe that they provide useful (although incomplete) pictures that help us assess the validity of the concept of a "movement society."

Importantly, we examine opinions about different forms of protest. Although earlier studies assumed differences between acts seen as "protest" and those seen as "riots," we see a need for more nuanced distinctions among the various types of actions that constitute standard repertoires of protest. As Gamson (1990) notes, protest tactics vary in their levels of disruption, and it is reasonable and plausible to expect that people's acceptance of protest will vary by the extent to which protest is seen as disruptive for the public (see also Thomas and Louis 2014). For instance, the public may be more likely to accept peaceful marches than more violent confrontations. Second, while some research points to changes in public opinion about protest in the aftermath of powerful events, such as the assassination of political leaders (Meyer 1969; Yuchtman-Yaar and Hermann 1998), the literature on public opinion about protest as a whole has not yet explored the notion that the acceptance of protest may have a temporal and historical component. But if the U.S. is indeed becoming a "movement society," we would expect to see increased acceptance of all types of protest over time. Our inquiry therefore features a longitudinal study of the public acceptance of protest, one that examines a variety of different types of protest activities, and explores whether protest is accepted equally by different segments of society. In the next section, we state our hypotheses more formally. 


\section{Hypotheses}

Our first and second research questions focus on the extent to which the public accepts protest, and whether or not public acceptance of protest has changed over time. As noted above, if the U.S. has become a "movement society," we would find substantial and growing acceptance of various types of protest. We therefore hypothesize:

H1: Public acceptance of all forms of protest will be greater in 2006 than in 1985.

Our last research question focuses on whether protest acceptance varies across social locations or is shared more generally by a broad cross-section of society. The concept of a movement society implies that protest is seen as legitimate by all or most members of the society. If that is the case, then we would not expect to find differences in the acceptance of protest among groups characterized by social locations such as race, class, gender, and age; instead, we would expect that acceptance of protest is more widespread (Meyer and Pullum 2015). However, previous research on public opinion about protest shows that some individual characteristics such as age, race, occupation, and education are statistically significant predictors of attitudes toward protest (Hall, Rodeghier, and Useem 1986; Rodeghier, Hall, and Useem 1991). Hall et al. (1986) in particular explain four possible mechanisms for how education, which has been found to be the most important predictor of such attitudes, affects attitudes toward protest: more education is associated with 1) stronger support of civil and political liberties; 2) intolerance of violence; 3) more identification with protest; and 4) more knowledge of the justifications for protest (see also Hall and Rosenthal 1981). To adjudicate between these two competing sets of expectations, we hypothesize:

H2: Demographic and socio-economic characteristics of individuals predict their acceptance of protest.

In addition to socio-demographic factors, social engagement may have an effect on public support for protest. It has been consistently found that individuals with connections to organizations or activists are more likely to participate in social movements (Fernandez and McAdam 1988; Jasper and Poulson 1995; McAdam 1988; McAdam and Paulsen 1993; Snow et al. 1980); similarly, membership in political or civic organizations and networks with others who find protest acceptable may shape one's perspective on protest. This expectation is also in line with Barkan's (2004) study of support for the environmental movement, which uses elements of Verba et al.'s (1995) "civic volunteerism model"; following that model, Barkan argues that participation in networks such as voluntary organizations can affect support for the movement. Extending these findings, we hypothesize as follows:

H3: People who are more socially engaged through volunteerism or civic organizations are more likely to accept protest than those are less socially engaged.

Lastly, the acceptance of protest is a political attitude, and may therefore be shaped by political engagement. Informed by the political science literature, Schussman and Soule's (2005) study of protest participation emphasizes the importance of five dimensions of political engagement: 1) political interest; 2) political efficacy; 3) political knowledge; 4) party affiliation; 
and 5) political orientation. Similarly, Corrigall-Brown (2012:18) argues that ideological factors, such as political efficacy, can shape sympathy for social movements. We extend their work to hypothesize that political engagement has a positive relationship with the acceptance of protest. As we explain in more detail below, our dataset only provides indicators of three of the five dimensions used by Schussman and Soule (2005). Therefore, we hypothesize the following: H4: Democrats and people with more liberal views or more interest in politics are more likely to accept protest than Republicans and people with more conservative views or less interest in politics, respectively.

\section{Data and Methods}

We test our hypotheses using repeated cross-sectional data from the General Social Survey from 1985, 1990, 1996 and 2006, with the last year being the most recent year for which GSS respondents were asked for their attitudes about protest. The GSS data use a multi-stage area probability sample to the block level and then use quota sampling based on sex, age, and employment status at the block level (NORC 2013:2868). To best represent the parameters of the population, this study invokes weights and accounts for clustering. Although our outcome variables are available at all four time points, we lack data for our explanatory variables for some years. Socio-demographic and political engagement variables are available for all four time points, but measures of social engagement are available only in 1990 and 1996. Therefore, we use 1990 and 1996 data for some analyses (i.e., the individual-level regression analysis) and data from all four time points for the descriptive statistics and the other analyses (i.e., the age-periodcohort analysis).

Initially, we dealt with missing data by using multiple imputation (Little and Rubin 1987; von Hippel 2007). However, the imputation increased only about 11.5 percent of the sample size for all the full models. In addition, the analysis with multiply imputed data produced largely the same conclusions as the analysis with listwise deleted data (cf., Allison 2001) ${ }^{1}$. Therefore, this study reports regression analysis results from listwise deleted data.

\section{Measures}

The outcome variables, acceptance of various forms of protest, are measured by three items. Respondents were asked if they thought three specific forms of protest should be allowed: 1) public meetings to protest against the government; 2) protest marches and demonstrations; and 3) a nationwide strike of all workers ${ }^{2}$. In the original data set, respondents were asked to rate the items with a four point scale from definitely not allowed (1) to definitely allowed (4). We recode and collapse the four response categories into two-i.e., acceptance (1) and non-acceptance (0). The 1990-1996 pooled data allow us to include three sets of explanatory variables that are hypothesized to affect the acceptance of protest. We use eight variables representing sociodemographic factors: a) age; b) educational attainment; c) income; d) labor force status, e) marital status, f) the existence of household member(s) less than 6 years old; g) sex, and h) race. Second, social engagement is indicated by measures of either organizational membership or 
volunteering. In 1990, respondents were asked to report the number of civic organizations of which they are a member. In 1996, respondents were asked to report the number of areas in which they have done volunteer work. These two indicators show a similarly right-skewed distribution, suggesting that they may be proxies of the same concept. Third, political engagement is measured by three items: a) party affiliation from strong Republican to independent and strong Democrat; b) political views from extremely conservative to extremely liberal; and c) interest in politics. Lastly, a dummy variable of the 1996 wave is used to control for time. Summary statistics for the explanatory and control variables are reported in Appendix A and full instruments are included in Appendix B.

\section{Analytic Strategy}

Data analyses in this study are conducted in two phases. First, we use descriptive statistics to examine changes in the public's acceptance of protest over time. Then, upon finding substantial changes between 1985 and 2006, we conduct an age-period-cohort analysis to tease out the age, period, and cohort effects on these changes. As we explain in more detail below, we are particularly interested in the relative impacts of period and cohort effects for the variance in the acceptance of protest (cf. Caren et al. 2011). A cross-classified random effects model (CCREM) enables us to estimate the effects of the embeddedness of respondents in survey periods and birth-cohorts while accounting for age effects (Raudenbush and Bryk 2002; Yang and Land 2013). As a hierarchical mixed effects model, the model treats age as level-1 fixed effect and period and cohort as level-2 random effect. ${ }^{3}$

Second, we conduct logistic regression with data from 1990 and 1996. To do so, we first test whether the individual-level relationships have changed from 1990 to 1996, using a changing parameter model (Firebaugh 1997, 42-63). Upon finding no evidence of change in the relationships, we conduct logistic regression with the pooled data. It should be noted that the descriptive statistics for the outcome variables adjust for weighting and account for clustering while the regression analysis uses un-weighted data, as the variables used to construct the weights are in the regression models (NORC 2013, 2868; Winship and Radbill 1994).

\section{Findings}

\section{Changes in the Acceptance of Protest}

Table 1 presents descriptive statistics for the three outcome variables in 1985, 1990, 1996, and 2006. ${ }^{4}$ It clearly shows that respondents' acceptance of protest, across all forms of protest, notably increased from 1985 to 2006, and provides support for the first hypothesis. ${ }^{5}$ It also shows that the less socially disruptive the form of protest is, the more likely that people find it acceptable. For instance, marches and demonstrations are tolerated much more than a nationwide strike, but they are tolerated slightly less than public meetings. Still, it is noteworthy that Americans find marches and demonstrations almost as equally acceptable as public meetings. Most notably, the acceptance of a nationwide strike increased two-fold over the 21 year time period. While only about 1 in 5 respondents accepted this much more disruptive form 
of protest in 1985, more than 2 in 5 found it acceptable in 2006. In comparison with the data from 1985, the acceptance of public meetings and demonstrations increased 9 and 26 percent, respectively.

\section{(Insert Table 1 about here)}

To better understand these changes over time, we conduct an age-period-cohort analysis. As described earlier, this analytic strategy enables us to evaluate the relative impacts of period and cohort effects on attitudes about protest while accounting for age effects. This strategy therefore helps us separate out general, societal-level effects affecting all members of a society from specific, cohort or generation-based effects. Period effects are due to many events and experiences that virtually all members of the society share. They bring about similar changes for individuals of all ages (Yang 2008). On the other hand, cohort effects represent the effects of formative experiences (Ryder 1965) and the subsequent sharing of the same historical and social events at about the same age (Yang and Land 2013). In other words, they are the effects of generational experiences. As such, they are not necessarily similar among individuals across different cohorts. By further examining what drives changes in public opinion about protest over time, and, especially, by inquiring about factors that shape all societal members (as opposed to distinct segments of society), we are able to take a more detailed look at what may be evidence of a "movement society."

Table 2 shows the results from the hierarchical mixed effects model. The key finding in the table is the level-2 intercept variance estimates. The variance statistic points to the extent to which acceptance varies by cohorts or survey periods. In other words, the larger variances in acceptance are associated with larger differences between periods or cohorts. For public meetings and demonstrations, the estimates for period are about twice as large as the estimates for cohort. For a nationwide strike, the difference gets even bigger. In sum, period effects are, for all types of protest, substantially stronger than cohort effects.

\section{(Insert Table 2 about here)}

This does not mean cohort effects do not matter, however. As Figure 1(B) shows, two birth cohorts (1939-1948 and 1949-1958) are more likely to accept protest than the cohort right next to them (1959-1968). Still, these cohorts are less likely to accept protest than the latest cohorts in our sample (1969-1978 and 1979-1988). All in all, the findings point to a broad societal-level change that is driving changes in public acceptance of protest over time. We reflect on these findings further in our Conclusion. Lastly, it is worth noting that the relative impact of cohort effects gets even smaller when it comes to a nationwide strike. This finding provides further evidence of a meaningful distinction among different forms of protest.

\section{(Insert Figure 1 about here)}

\section{Individual-level Patterns of Acceptance}

While our analyses so far find notable patterns in the public's growing acceptance of protest, we are also interested in individual-level patterns. We turn now to our final research question: What predicts whether or not members of the public find protest acceptable? Table 3 
presents the results from the logistic regression of acceptance of protest on socio-demographic factors and indicators of social and political engagement. Overall, it is noteworthy that the patterns of acceptance for public meetings and marches and demonstrations are similar.

However, there is a notable difference between these patterns and those for the acceptance of a nationwide strike.

\section{(Insert Table 3 about here)}

As Table 3 shows, socio-demographic variables are found significant for the acceptance of protest. Age and education have a relationship with the acceptance of public meetings and marches and demonstrations. Younger and more educated people are more likely to accept protest than the older and the less educated. Those in school are more likely to accept marches and demonstrations than those who work full time. The statistical significance of being in school also supports research finding that college campuses are a protest-friendly environment (Van Dyke 1998). We also find that parental status and income are marginally significant ${ }^{6}$. Those without young children and people with higher income are more likely to accept public meetings and demonstrations, respectively. Further, whites and men are more likely to accept public meetings than are racial minorities and women, respectively. Men are more likely to accept marches and demonstrations than are women. These findings show that the acceptance of protest does vary by social location, supporting our second hypothesis. In addition, the statistical significance of the 1996 dummy variable further supports the first hypothesis, showing that the acceptance of protest has increased over time.

The third hypothesis is not supported in the complete models reported in Table 3, but it is still noteworthy that social engagement is significant in a partial model (not shown here). ${ }^{7}$ This finding suggests that though social engagement has a relationship with the acceptance of protest, the effect of this variable can be explained by other predictors. As for political engagement, the analysis finds some evidence supporting the fourth hypothesis. Those who are more interested in politics are more likely to accept public meetings and marches and demonstrations.

Findings also suggest that the acceptance of a nationwide strike is explained differently than the acceptance of the other two forms of protest, and therefore provide further evidence of a meaningful distinction between different forms of protest. Income, which is positively associated with the acceptance of meetings and demonstrations, is negatively associated with the acceptance of a nationwide strike. In other words, people with higher incomes are more likely to accept meetings and demonstrations but are less likely to accept a nationwide strike than are people with lower incomes. This finding is particularly surprising in light of the positive correlation between education and income (correlation coefficient $r=.32$; see Appendix C). Still, it should also be noted that socio-demographic factors and political engagement are in general found positively associated with the acceptance of a nationwide strike, as they are with other types of protest. Age and education still have a significant relationship with the acceptance of a nationwide strike; party affiliation and political views, in addition to political interests, are also significant predictors of this outcome, even though they did not significantly predict the acceptance of meetings and demonstrations. 
In sum, the regression results provide strong support for the second and fourth hypotheses and weak support for the third hypothesis. But more importantly, the results reveal some nuances in the patterns of acceptance across different forms of protest. The acceptance of public meetings and the acceptance of demonstrations operate relatively similarly, while the acceptance of a nationwide strike shows a notable difference, as the effect of income is reversed from positive to negative. We elaborate further on the implications of this and other findings in our discussion.

\section{Discussion and Conclusions}

Public opinion is one component of the broader environment in which social movements operate. Thus, to fully understand social movements, we argue that it is necessary to understand the public acceptance of protest. Using GSS data from a roughly twenty-year span, we have found that the public has grown more accepting of protest over time. People are more likely to approve of meetings and demonstrations than general strikes, but between 1985 and 2006 there is clear evidence of increasing acceptance of a variety of forms of protest. As scholars have argued (e.g., Meyer and Tarrow 1998), protest has become a legitimate part of American politics.

The age-period-cohort analysis helps us better understand these changes in the acceptance of protest in the United States, and adds more depth to our exploration of the "movement society" thesis. In another recent longitudinal study, albeit one that studies patterns in protest participation rather than public opinion, Caren et al. (2011) found evidence of cohort effects in protest participation over time; they therefore suggested that the U.S. has a social movement "generation" rather than a movement society. We also find substantial generational or cohort effects on attitudes toward protest. However, our analysis shows that period effects are stronger than cohort effects for the acceptance of protest, and therefore lends support to the movement society thesis.

This contrast points to the difference between behaviors and attitudes. It makes sense that period effects, which speak to societal level influences that affect all or most members of a society, may have more of an impact on attitudes than on behaviors. For instance, when a social norm regarding protest or a method of political participation changes, it would still be more difficult to for the public to change their behavior and participate in protest than to change their attitudes and accept this relatively new method of political participation. In this sense, our findings may be compatible with Caren et al.'s (2011). Nevertheless, our findings also imply that the 1960s might have not been a "short-lived interruption" (Caren et al. 2011:126) but a landscape-altering period after which protest increasingly became a standard, accepted feature of American politics.

Further, we examined how social location, social engagement, and political engagement help explain the variations in these attitudes among individuals. For the most part, the regression analysis shows that younger and more educated people are more likely to accept all types of protest than are older and less educated people. Labor force status and parental status have effects on some outcome variables. Men are more likely to accept all types of protest than are women. Such findings go against the concept of a movement society, since they indicate that the 
acceptance of protest is not widespread across society but instead varies by social location.

Our study failed to find an independent effect of social engagement on the acceptance of protest. Whereas previous research found that participation in social networks is a consistently significant predictor of individual participation in social movements (Fernandez and McAdam 1988; McAdam and Paulsen 1993), these findings do not extend to protest acceptance. Of course, the insignificance could be due to the difference between acceptance of protest (an attitude) and participation in protest (a behavior). However, the hypothesis on political engagement is supported. Democrats and people with more liberal views are more likely to accept a general strike than Republicans and people with more conservative views. People with more interest in politics are more likely to accept all three forms of protest than people with less interest in politics. It is notable that political interest is the most consistently significant predictor among the political engagement variables.

One of the most interesting findings centered on differences in the patterns of support for various types of protest activities. As we found, the effect of some socio-demographic factors on the acceptance of protest is contingent upon the nature of protest. Notably, higher income people are more likely to accept marches and demonstrations than are lower income people, while this effect is reversed when it comes to a nationwide strike. These findings substantiate a Marxist perspective on political culture, and are in line with neo-Marxist analyses of various social phenomena (see Manza and McCarthy 2011). We can interpret these findings in light of the importance of social location: powerful, higher-status individuals may be more tolerant of less disruptive acts of protest such as meetings and demonstrations that do not threaten their material position, but may be less tolerant of general strikes that may hurt them substantially or symbolically. However, these findings deserve further inquiry, especially in light of findings that show the complex ways in which power shapes people's sense of what is in their own interest (see Gaventa 1980).

More broadly, we believe that our findings help illuminate the concept of a movement society. First and foremost, our findings show that there are limits to the boundaries of the movement society. While protest is increasingly acceptable, the analysis shows that not all forms of protest are equally acceptable in the eyes of the public. Though the acceptance of a nationwide strike has been dramatically increased, the majority still does not find it acceptable. Further, the limits of the movement society may be determined by social location: depending on their position within the society, some members find some forms of protest more acceptable than others. The concept of a social movement society is therefore more complex than current treatments would suggest. Yet this should not be surprising: like any society, the movement society is stratified, with different subgroups occupying positions that shape their perspectives on societal issues. Our findings about the stratification of acceptance may be useful toward further development and testing of the concept of the movement society.

Lastly, while we think our findings are useful, we believe that they warrant further exploration. In particular, we suggest that future research on the public acceptance of protest employ cross-national data. While the notion of the social movement society is based on the U.S. 
case, examinations of public acceptance of protest in different countries are worthwhile. A basic but noteworthy finding in this study is that Americans are less tolerant of the idea of a nationwide strike than they are of less disruptive forms of protest. While this may not be surprising for respondents in the U.S., it is worth asking whether such attitudes vary by national cultures. The use of general social surveys in other democracies can tap into this question, making for a good cross-national comparison with regard to political culture in general and the tolerance of protest in particular. Such studies will continue to improve our understanding of the political environments in which social movements operate.

${ }^{1}$ The analysis with the multiply-imputed sample is available as an online supplement at the first author's website (http://park460.wixsite.com/spark). The supplement also includes the analyses on each wave of data.

${ }^{2}$ We acknowledge that disruptiveness may not be the only property that characterizes these three types of protest; for instance, strikes are usually limited to labor issues, while meetings and marches can cover broader terrain. Further, we recognize that the meaning of "a nationwide strike" may not be clear to respondents, and for some respondents the legitimacy of the strike may depend on the particular job sector. Nonetheless, we argue that it is useful to examine opinions about different types of protest.

${ }^{3}$ A cross-classified random effects model (CCREM), in principle, allows one to include more individuallevel variables in the analysis. However, given the small number of survey periods, we lack enough statistical power to do so. Therefore, with this model, we found it the most appropriate to focus on the examination of the relative impact of period and cohort effects.

${ }^{4}$ Descriptive statistics for the unweighted sample are available upon request. The two sets of results for the weighted and unweighted samples are very similar and the modal change the adjustment made is an increase of .002. The biggest difference is a decrease of .015 for the acceptance of a nationwide strike in 2006.

${ }^{5}$ A two-sample $t$ test shows that all the mean differences for acceptance of protest in 1985 and 2006 are statistically significant: the t statistic is $4.3021(p<.001)$ for public meetings; $9.0498(p<.001)$ for marches and demonstrations; and $9.5719(p<.001)$ for a nationwide strike.

${ }^{6}$ The $p$ value for each predictor is .054 and .052 . These predictors were significant at a traditional significance level in an earlier analysis (not shown). For the current analysis, we recoded labor force status so that "keeping house" and "not working" are collapsed into "not working for pay." We did so in order to address a collinearity issue in the data (i.e., sex is an almost perfect predictor of "keeping house" in our data because $96 \%$ of those who responded "keeping house" are women).

${ }^{7}$ Partial models are not reported but are available upon request. 


\section{References}

Agnone, Jon. 2007. "Amplifying Public Opinion: The Policy Impact of the U.S. Environmental Movement." Social Forces 85(4):1593-1620.

Allison, Paul D. 2001. Missing Data. Thousand Oaks, CA: Sage.

Barkan, Steven E. 2004. "Explaining Public Support for the Environmental Movement: A Civic Voluntarism Model.” Social Science Quarterly 85(4):913-937.

Berkowitz, William R. 1973. "Effects of Anti-Vietnam War Demonstrations on Public Opinion and Policy in the U.S." Social Science Research 2(1):1-14.

Boutcher, Steven. 2013. "Lawyering For Social Change: Pro Bono Publico, Cause Lawyering, and the Social Movement Society." Mobilization 18(2):179-196.

Burstein, Paul. 1979. "Public Opinion, Demonstrations, and the Passage of Antidiscrimination Legislation." The Public Opinion Quarterly 43(2):157-172.

Burstein, Paul, and William Freudenberg. 1978. "Changing Public Policy: The Impact of Public Opinion, Antiwar Demonstrations, and War Costs on Senate Voting on Vietnam War Motions." American Journal of Sociology 84(1):99-122.

Burstein, Paul, and April Linton. 2002. "The Impact of Political Parties, Interest Groups, and Social Movement Organizations on Public Policy: Some Recent Evidence and Theoretical Concern.” Social Forces 81(2):380-408.

Caren, Neal, Raj Andrew Ghoshal, and Vanesa Ribas. 2011. "A Social Movement Generation: Cohort and Period Trends in Protest Attendance and Petition Signing." American Sociological Review 76(1):125-151.

Corrigall-Brown, Catherine. 2011. Patterns of Protest: Trajectories of Participation in Social Movements. Stanford, CA: Stanford University Press.

Crozat, Matthew. 1998. “Are the Times A-Changin'? Assessing the Acceptance of Protest in Western Democracies." Pp. 59-81 in The Social Movement Society, edited by David S. Meyer and Sidney G. Tarrow. Lanham, MD: Rowman \& Littlefield.

Ennis, James G., and Richard Schreuer. 1987. "Mobilizing Weak Support for Social Movements: The Role of Grievance, Efficacy, and Cost.” Social Forces 66(2):390-409.

Fernandez, Roberto, and Doug McAdam. 1988. "Social Networks and Social Movements: MultiOrganizational Fields and Recruitment to Mississippi Freedom Summer." Sociological Forum 3(3):357-382.

Firebaugh, Glenn. 1997. Analyzing Repeated Surveys. Thousand Oaks, CA: Sage.

Gamson, William A. 1990. The Strategy of Social Protest ( $2^{\text {nd }}$ edition). Belmont, CA: Wadsworth Publishing.

Gaventa, John. 1980. Power and Powerlessness: Quiescence and Rebellion in an Appalachian Valley. Urbana and Chicago: University of Illinois Press.

Hall, Robert L., and Saul F. Rosenthal. 1981. "Education and Antagonism to Protest." Journal of Political and Military Sociology. 9(1):73-82.

Hall, Robert L., Mark Rodeghier, and Bert Useem. 1986. "Effects of Education on Attitude to Protest." American Sociological Review 51(4):564-573.

Jacobs, David, and Stephanie L. Kent. 2007. "The Determinants of Executions since 1951: How Politics, Protests, Public Opinion, and Social Divisions Shape Capital Punishment." Social Problems 54(3):297-318.

Jasper, James M. 1997. The Art of Moral Protest. Chicago: University of Chicago Press.

Jasper, James M., and Jane Poulson. 1995. "Recruiting Strangers and Friends: Moral Shocks and Social Networks in Animal Rights and Animal Protest." Social Problems 42(4):493-512. 
Jenkins, J. Craig, Michael Wallace and Andrew S. Fullerton. 2008. "A Social Movement Society? A Cross-National Analysis of Protest Potential." International Journal of Sociology 38(3):12-35.

Little, Roderick J. A., and Donald B. Rubin. 1987. Statistical Analyses with Missing Data. New York: Wiley.

Manza, Jeff, and Clem Brooks. 2012. "How Sociology Lost Public Opinion: A Genealogy of a Missing Concept in the Study of the Political." Sociological Theory 30(2): 89-113.

Manza, Jeff, and Michael A. McCarthy. 2011. "The Neo-Marxist Legacy in American Sociology." Annual Review of Sociology 37: 155-183.

McAdam, Doug. 1982. Political Process and the Development of Black Insurgency, 1930-1970. Chicago, IL: University of Chicago Press.

McAdam, Doug. 1988. Freedom Summer. New York: Oxford University Press.

McAdam, Doug, and Hilary Boudet. 2012. Putting Social Movements in Their Place: Explaining Opposition to Energy Projects in the United States, 2000-2005. New York: Cambridge University Press.

McAdam, Doug, John D. McCarthy, and Mayer Zald. 1996. "Introduction: Opportunities, Mobilizing Structures, and Framing - Toward a Synthetic Comparative Perspective on Social Movements.” Pp. 1-20 in Comparative Perspectives on Social Movements, edited by IDEM. New York: Cambridge University Press.

McAdam, Doug, and Ronnelle Paulsen. 1993. "Specifying the Relationship Between Social Ties and Activism." American Journal of Sociology 99(3):640-667.

McAdam, Doug, and Yang Su. 2002. "The War at Home: Antiwar Protests and Congressional Voting, 1965 to 1973." American Sociological Review 67(5):696-721.

McCright, Aaron M., and Riley Dunlap. 2008. "The Nature and Social Bases of Progressive Social Movement Ideology: Examining Public Opinion toward Social Movements." The Sociological Quarterly 49(4):825-848.

Meyer, David S. 1993. "Institutionalizing Dissent: The United States Structure of Political Opportunity and the End of the Nuclear Freeze Movement." Sociological Forum 8(2):157-179.

Meyer, David S. and Amanda Pullum. 2015. "Reconsidering the Social Movement Society in the New Century." Pp. 23 - 41 in Protest and Politics: The Promise of Social Movement Societies, edited by Howard Ramos and Kathleen Rodgers. Vancouver: UBC Press.

Meyer, David S., and Sidney Tarrow, eds. 1998. The Social Movement Society: Contentious Politics for a New Century. Lanham, MD: Rowman \& Littlefield

Meyer, Philip. 1969. "Negro Militancy and Martin Luther King: The Aftermath of Martyrdom." The Public Opinion Quarterly 33(2):160-173.

National Opinion Research Center. 2013. “General Social Surveys, 1972-2012: Cumulative Codebook." University of Chicago.

Nepstad, Sharon Erickson, and Christian Smith. 1999. "Rethinking Recruitment to High-Risk/Cost Activism: The Case of Nicaragua Exchange." Mobilization 4(1):25-40.

Perrin, Andrew J., and Katherine McFarland. 2011. "Social Theory and Public Opinion." Annual Review of Sociology 37: 87-107.

Raudenbush, Stephen W. and Anthony S. Bryk. 2002. Hierarchical Linear Models: Applications and Data Analysis Methods. Thousand Oaks, CA: Sage.

Rodeghier, Mark, Robert L. Hall, and Bert Useem. 1991. "How Education Affects Attitude to Protest: A Further Test.” The Sociological Quarterly 32(2):277-288. 
Ryder, Norman B. 1965. "The Cohort as a Concept in the Study of Social Change." American Sociological Review 30(6):843-861.

Schussman, Alan, and Sarah A. Soule. 2005. "Process and Protest: Accounting for Individual Protest Participation." Social Forces 84(2):1083-1106.

Snow, David A., Louis A. Zurcher Jr., and Sheldon Ekland-Olson. 1980. "Social Networks and Social Movements: A Microstructural Approach to Differential Recruitment." American Sociological Review 45(5):787-801.

Soule, Sarah A., and Jennifer Earl. 2005. "A Movement Society Evaluated: Collective Protest in the United States, 1960-1986." Mobilization 10(3):345-364.

Tarrow, Sidney G. 1994. Power in Movement. Cambridge: Cambridge University Press.

Taylor, Verta. 2000. "Mobilizing for Change in a Social Movement Society." Contemporary Sociology 29(1):219-230.

Thomas, Emma F., and Winnifred R. Louis. 2014. "When Will Collective Action Be Effective? Violent and Non-Violent Protests Differentially Influence Perceptions of Legitimacy and Efficacy among Sympathizers." Personality and Social Psychology Bulletin 40(2):263276.

Turner, Ralph H. 1969. “The Public Perception of Protest.” American Sociological Review 34(6):815-831.

Turner, Ralph H. 1970. "Determinants of Social Movement Strategies.” Pp. 145-164 in Human Nature and Collective Behavior: Papers in Honor of Herbert Blumer, edited by Tamotsu Shibutani. Englewood Cliffs, NJ: Prentice-Hall.

Useem, Bert and Michael Useem. 1979. "Government Legitimacy and Political Stability." Social Forces 57(3):840-852.

Van Dyke, Nella. 1998. "Hotbeds of Activism: Locations of Student Protest." Social Problems 45(2):205-220.

Verba, Sidney, Kay Lehman Schlozman, and Henry E. Brady. 1995. Voice and Equality: Civic Voluntarism in American Politics. Cambridge: Harvard University Press.

Von Hippel, Paul T. "Regression with Missing Ys: An Improved Strategy for Analyzing Multiply Imputed Data." Sociological Methodology 37(1):83-117.

Weaver, Alicia. 2008. "Does Protest Behavior Mediate the Effects of Public Opinion on National Environmental Policies?: A Simple Question and a Complex Answer." International Journal of Sociology 38(3):108-125.

Winship, Christopher, and Larry Radbill. 1994. "Sampling Weights and Regression Analysis." Sociological Methods and Research 23(2):230-257.

Yang, Yang, and Kenneth C. Land. 2013. Age-Period-Cohort Analysis: New Models, Methods, and Empirical Applications. Boca Raton, FL: CRC Press.

Yuchtman-Yaar, Ephraim, and Tamar Hermann. 1998. "The Latitude of Acceptance: Israeli Attitudes toward Political Protest before and after the Assassination of Yitzhak Rabin.” Journal of Conflict Resolution 42(6):721-743. 
Table 1. Summary Statistics for the Outcome Variables, the General Social Survey (19852006)

\begin{tabular}{lllll}
\hline Variable & $\begin{array}{l}1985 \\
(\mathrm{~N}=574)\end{array}$ & $\begin{array}{l}1990 \\
(\mathrm{~N}=1053)\end{array}$ & $\begin{array}{l}1996 \\
(\mathrm{~N}=1188)\end{array}$ & $\begin{array}{l}2006 \\
(\mathrm{~N}=1472)\end{array}$ \\
\hline Public Meetings & $.788(.409)$ & $.772(.419)$ & $.839(.367)$ & $.859(.348)$ \\
Marches and Demonstrations & $.667(.472)$ & $.723(.448)$ & $.806(.395)$ & $.841(.366)$ \\
A Nationwide Strike & $.203(.403)$ & $.264(.441)$ & $.410(.492)$ & $.403(.491)$
\end{tabular}

Note: Adjusted means are shown with standard deviations in parenthesis. The outcome variables are coded as 1 for acceptance and 0 for non-acceptance. 
Table 2. Random Intercept Models for the Acceptance of Protest with Fixed Effects for Age of Respondents, 1985-2006

\begin{tabular}{llll}
\hline & Public Meetings & $\begin{array}{l}\text { Marches and } \\
\text { Demonstrations }\end{array}$ & $\begin{array}{l}\text { A Nationwide } \\
\text { Strike }\end{array}$ \\
\hline $\begin{array}{l}\text { Constant } \\
\text { Level-2 Intercept }\end{array}$ & $2.297 * * *(.238)$ & $2.002 * * *(.319)$ & $.175(.285)$ \\
Variance Estimates & & & \\
$\quad$ Period & $.062(.049)$ & $.145(.110)$ & $.207(.152)$ \\
$\quad$ Cohort & $.036(.026)$ & $.071(.047)$ & $.029(.021)$ \\
Age (Fixed Effect) & $-.018^{* * *(.004)}$ & $-.020^{* * *}(.005)$ & $-.023 * * *(.003)$ \\
BIC & 4247.0 & 4604.2 & 5446.1 \\
$\mathrm{~N}$ & 4,529 & 4,492 & 4,412 \\
\hline
\end{tabular}

Note: Unstandardized coefficients are shown with standard errors in parentheses. Four survey periods and eight birth cohorts are included in the modeling. ${ }^{*} \mathrm{p}<.05 ;{ }^{* *} \mathrm{p}<.01 ;{ }^{* * *} \mathrm{p}<.001$ 
Table 3. Logistic Regression of Acceptance of Protest, 1990-1996 (N=1,393)

\begin{tabular}{|c|c|c|c|}
\hline & Public Meetings & $\begin{array}{l}\text { Marches and } \\
\text { Demonstrations }\end{array}$ & $\begin{array}{l}\text { A Nationwide } \\
\text { Strike }\end{array}$ \\
\hline Age & $.980 * *(.006)$ & $.978 * * *(.006)$ & $.976^{* * *}(.005)$ \\
\hline Education & $1.272 * * *(.042)$ & $1.274 * * *(.041)$ & $1.111 * * *(.028)$ \\
\hline Income & $1.098(.066)$ & $1.122 \dagger(.066)$ & $.882 *(.045)$ \\
\hline \multicolumn{4}{|l|}{$\begin{array}{l}\text { Labor force status } \\
\text { (Ref: Full-time) }\end{array}$} \\
\hline Part-time & $1.601(.452)$ & $1.309(.337)$ & $1.063(.216)$ \\
\hline Not working for pay & $1.256(.276)$ & $1.101(.229)$ & $.826(.153)$ \\
\hline Retired & $.955(.282)$ & $.724(.202)$ & $.608(.180)$ \\
\hline In school & $2.144(1.251)$ & $9.994 *(10.368)$ & $1.294(.467)$ \\
\hline Married & $.836(.143)$ & $1.079(.175)$ & $.970(.133)$ \\
\hline Young children & $.673 \dagger(.138)$ & $.732(.147)$ & $.884(.143)$ \\
\hline Sex (Men) & $1.634 * *(.265)$ & $1.487 *(.269)$ & $1.418^{* *}(.180)$ \\
\hline Race (White) & $1.835 * *(.382)$ & $1.259(.264)$ & $.926(.160)$ \\
\hline Party affiliation & $1.072(.044)$ & $1.076(.042)$ & $1.107 * *(.038)$ \\
\hline Political views & $.995(.059)$ & $1.091(.062)$ & $1.153 * *(.055)$ \\
\hline Political interest & $1.244 * *(.090)$ & $1.159 *(.080)$ & $1.158 *(.068)$ \\
\hline Social engagement & $.941(.050)$ & $.938(.047)$ & $1.042(.043)$ \\
\hline 1996 wave & $1.732 * *(.291)$ & $1.752 * * *(.280)$ & $1.937 * * *(.264)$ \\
\hline Constant & $.059 * * *(.037)$ & $.054 * * *(.032)$ & $.084 * * *(.040)$ \\
\hline Pseudo R-square & .131 & .151 & .096 \\
\hline
\end{tabular}

Note: Odds ratios are shown with standard errors in parentheses. The outcome variable is coded as 1 for acceptance and 0 for non-acceptance. $\dagger \mathrm{p}<.1 ; * \mathrm{p}<.05 ; * * \mathrm{p}<.01 ; * * * \mathrm{p}<.001$ 
Figure 1. Acceptance of Protest in the US General Social Survey, 1985-2006

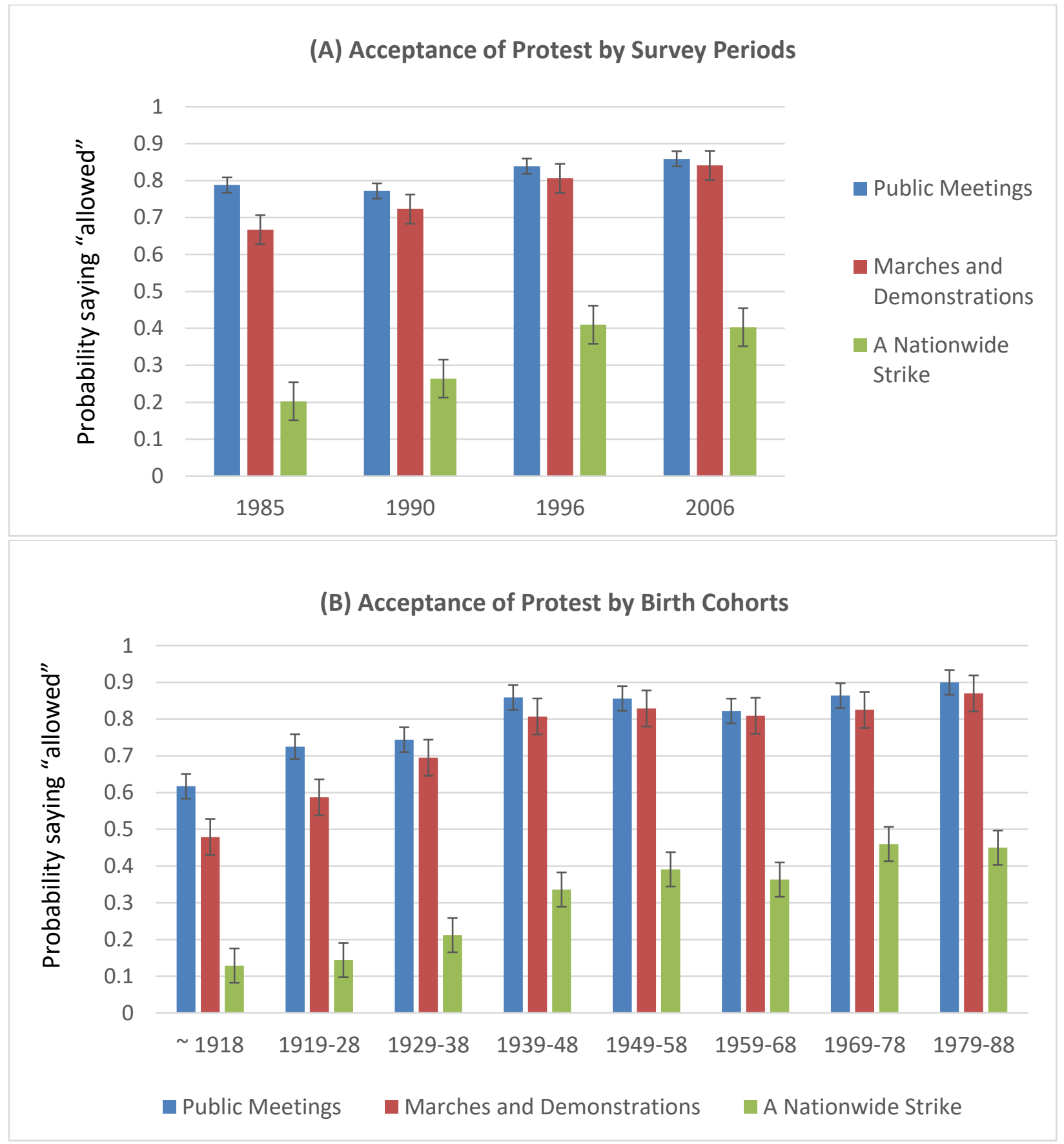

Note: Charts are created using adjusted means. 
Appendix A. Descriptive Statistics for All Explanatory and Control Variables (1990-1996; $N=1393$ )

\begin{tabular}{lllll}
\hline Variable & Mean & SD & Min & Max \\
\hline Age & 43.352 & 16.079 & 18 & 89 \\
Education & 13.460 & 2.799 & 3 & 20 \\
Income & 4.001 & 1.469 & 1 & 5 \\
Labor force status & 2.119 & 1.578 & 1 & 6 \\
Married & .519 & .500 & 0 & 1 \\
Young children & .195 & .396 & 0 & 1 \\
Sex (Men) & .457 & .498 & 0 & 1 \\
Race (White) & .851 & .357 & 0 & 1 \\
Party affiliation & 4.088 & 2.021 & 1 & 7 \\
Political views & 3.795 & 1.374 & 1 & 7 \\
Political interests & 3.295 & 1.088 & 1 & 5 \\
Social engagement & 2.653 & 1.690 & 0 & 6 \\
1996 wave & .585 & .493 & 0 & 1 \\
\hline
\end{tabular}

